\title{
Em defesa de uma gestão compartilhada da medicação em psiquiatria
}

\section{| ${ }^{1}$ Maurino Loureiro do Nascimento |}

Resumo: A partir de uma discussão acerca do Guia de Acompanhamento da Gestão Autônoma da Medicação em Saúde Mental, resultado de um amplo projeto de saúde mental subvencionado pelo Ministério da Saúde do Canadá, proponho sustentar a relevância clínica do que prefiro denominar gestão compartilhada da medicação em saúde mental.

> Palavras-chave: medicação; psiquiatria; qualidade de vida; saúde coletiva; saúde mental.

1 Doutorado em Saúde Coletiva pelo IMS-UERJ e pós-doutorando em psiquiatria pelo Instituto de Psiquiatria da UFRJ. Supervisor da residência médica em psiquiatria PUC-PR. Endereço eletrônico: maurino. nascimento@hotmail.com 
A Gestão Autônoma da Medicação permite restituir poder à pessoa e reequilibrar sua relação com o médico. Você consegue tomar as rédeas da própria vida. Trabalhadora social, CLSC (RRASMQ; ÉRASME, 2006, p. 20)

Sou uma pessoa, não uma doença! MSSS, Relatório Harnois, 1987 (RRASMQ; ÉRASME, 2006, p. 27)

Um documento produzido em coparticipação com usuários, interventores, pesquisadores e organismos de defesa dos direitos em saúde mental expressa os esforços coletivos de elaboração de um movimento de pensamento que se propóe a "substituir à posição de objeto de tratamento e de doente a de sujeito e de pessoa de pleno direito" (RRASMQ; ÉRASME, 2006, p. 3, grifo meu).

Refiro-me ao Repèrespourune gestion autonome de la médication en santémentale: guide d'accompagnement, confeccionado conjuntamente pelo Regroupement des ressources alternatives en santé mentale du Québec (RRASMQ) e pela Association des groupes d'intervention en défense des droits en santé mentale du Québec (AGGIDD-SMQ), e subvencionado pelo Ministère de la Santé et des Services Sociaux e pelo Ministère du Développement économique, de l'Innovation et de l'Exportation du Québec.

Pressupondo o diálogo e a troca entre o médico e o paciente, a noção de "gestão autônoma da medicação em saúde mental”, surgida em 1998, no seio de um comitê de trabalho do RRASMQ, visa contemplar o anseio dos usuários dos serviços de saúde mental em "ver reconhecer sua experiência e seu saber próprios quanto ao impacto da medicação sobre sua vida.” (RRASMQ; ÉRASME, 2006, p. 6).

Trata-se, em suma, da inovadora proposta de um modelo de prática que tenha por princípio proporcionar um "espaço de conversação" em torno da medicação, a partir do qual os pacientes psiquiátricos em questão possam dar novos sentidos às suas experiências como usuários de psicotrópicos, podendo, assim, participar de forma mais ativa, consciente e consequente do processo terapêutico psicofarmacológico; em vez monitoramento sintomatológico, impessoal, unidimensional, unidirecional e, muitas vezes, inquestionavelmente impositivo, empreendido nos tratamentos medicamentosos tradicionais - haja vista que a experiência de sofrimento psíquico não se reduz à sintomatologia. 
Com o objetivo pragmático de melhorar a "qualidade de vida”, esse auspicioso projeto se funda na primazia da noção de pessoa, ou seja, sobre a necessidade ética de colocá-la no centro das decisões que a concernem no processo de tratamento. Com a finalidade de favorecer uma relação ativa, e não mais passiva, no tratamento farmacológico, ele visa ao que passou a ser definido como uma "reapropriação do poder" pelas pessoas que vivenciam problemas de saúde mental, a partir do reforço e do alargamento de sua "capacidade de ser e de agir":

Os princípios incontornáveis da Gestão Autônoma da Medicação em Saúde Mental são:

- a importância de uma qualidade de vida subjetiva;

- a (re) apropriação de poder;

- o reconhecimento das significações plurais da medicação;

- o respeito da pessoa, das suas decisões e dos seus direitos;

- uma abordagem ampla do sofrimento e do estar - melhor. (RRASMQ; ÉRASME, 2006, p. 21).

Haja vista o lugar central que o "saber legítimo" acerca da medicação psicotrópica ocupa nas práticas de saúde mental nos países ocidentais, não surpreende que existam poucos espaços interdisciplinares nos quais se possa falar dos medicamentos, seus efeitos, seus limites e seus aspectos simbólicos, tanto entre as pessoas concernidas e seus interventores quanto entre esses últimos. Nesse sentido, "a medicação continua sendo, muito frequentemente, um assunto tabu” (RRASMQ; ÉRASME, 2006, p. 19).

É no contrafluxo dessa tendência que a gestão autônoma da medicação em saúde mental busca, entre saberes múltiplos a esse respeito, criar tais espaços de diálogo, a partir dos quais se possa "favorecer uma partilha desses saberes" (RRASMQ; ÉRASME, 2006, p. 19). A meu ver, essa proposta se afina com a concepção do sociólogo Phillipe Pignarre, para o qual "curar é colocar o paciente em novas redes que o afetem de maneira coercitiva" (PIGNARRE, 1999, p. 147, grifo meu). Mas o que ele poderia estar querendo dizer com isso? E como essa afirmativa se coadunaria com o projeto da gestão autônoma da medicação?

Diferentemente de um carro ou um computador, cujos "valores de uso" são óbvios, o medicamento não tem um valor de uso identificável socialmente; melhor dizendo, o seu valor de uso é instável, ele inevitavelmente deve vir acompanhado da prescrição médica, a bem dizer, da instrução do especialista, que diz quando e como ele deve ser utilizado - e sem a qual não há como os consumidores se orientarem. 
É o médico que define as regras de seu consumo, pois os remédios não se definem "em si mesmos", só em sua aplicação a uma pessoa doente. É na consulta que o paciente saberá o que deve saber sobre um medicamento que será escolhido especificamente para ele. Assim, é por intermédio do médico que o medicamento se torna um "objeto socialmente estabilizado" (PIGNARRE, 1999, p. 127). A receita é um símbolo da autoridade médica, e é aí que, a meu ver, entra a discussão sobre a gestão autônoma da medicação, com a finalidade de, como define Pignarre, "reintroduzir o paciente" (p. 137).

Em minha concepção, o projeto de gestão autônoma da medicação em saúde mental visa a um processo mais amplo de "estabilização social" do objeto remédio, envolvendo múltiplos saberes e atores - sobretudo o próprio paciente. Assim, partilhar o "saber" sobre a medicação permitirá, parafraseando Donald Winnicott, um uso "suficientemente bom" dela. Todavia, a despeito de sua importância ética, teria essa proposta uma sustentação teórica?

Nas prolíficas pesquisas com o seu amigo Karl-Otto Apel, a respeito do que este chama de "ética da discussão", Habermas desenvolve algumas ideias inspiradoras em torno de seu conceito de "racionalidade comunicativa". Trata-se, em suma, do uso da linguagem orientado ao entendimento mútuo, ou seja, de uma espécie de "competição discursiva pelo melhor argumento" visando ao acordo, baseado no reconhecimento intersubjetivo, que vai sendo aos poucos alcançado pelos envolvidos na medida em que eles vão aceitando, no decorrer da conversa, determinadas pretensōes de verdade pelas mesmas razôes (HABERMAS, 2004, p. 109-117).

A “razão prática” (HABERMAS, 2007, p. 13) que se encontra em jogo aqui e pressupõe o que chamamos de verdade, não é predeterminada, mas, sim, produzse a partir de feixes contingentes de relaçôes intersubjetivas. Portanto, o "acordo racional" subentende que as soluções escolhidas "sejam racionalmente aceitáveis para todos os envolvidos e todos os que por elas forem afetados" (p. 16).

Esses estudos de Habermas basearam-se na denominada "virada pragmática", reclamada por Richard Rorty, para quem o pensamento depende da comunicação (RORTY, 1997, p. 173-204). Segundo Donald Davidson, um de seus principais interlocutores, "a fonte do conceito de verdade objetiva é a comunicação interpessoal" (DAVIDSON, 2001, p. 209). De acordo com um conceito seu, chamado "princípio de caridade", "na comunicação, o que um falante e o seu intérprete devem compartilhar é um entendimento sobre o que o falante quer dizer 
com o que ele fala” (p. 210). Assim, entendo que a construção coletiva de um saber sobre os medicamentos psicotrópicos poderia se basear nas ideias desses autores.

Portanto, o que eu proponho aqui é uma "sustentação clínica" da gestão autônoma da medicação - que, por sinal, prefiro chamar de compartilhada. A meu ver, o seu "propósito terapêutico" poderia se respaldar na afirmação de Rorty de que, as "crenças sugeridas por outras culturas precisam ser testadas através da tentativa de combiná-las com as que já possuímos.” (RORTY, 1997, p. 59).

A meu ver, essa assertiva de Rorty poderia levar-nos a repensar alguns aspectos da terapêutica medicamentosa. Refiro-me especificamente ao que eu chamaria aqui de sintonização entre sistemas de crenças na relação médico-paciente - que, tal qual o "princípio de caridade" de Davidson, seria o ajustar de um pensamento a outro.

Segundo Luc Boltanski, os pacientes têm maior ou menor familiarização com a nosografia médica, na medida em que a distância social entre eles e o seu médico é maior ou menor (BOLTANSKI, 1979, p 133). Mas, baseando-me em Rorty, preferiria dizer que a distância se dá entre "sistemas de crenças".

Ora, falar em sistemas de crenças significa dizer que as crenças são individualizadas e identificadas pelas suas relaçôes com outras crenças, isto é, elas dão suporte umas às outras. Portanto, temos de ter uma infinidade de crenças se quisermos ter alguma. Daí decorre que as crenças de alguém devem ser consistentes umas com as outras, caso contrário não seria possível qualquer identificação dos seus conteúdos. Nesse sentido, ser racional é ter um sistema de crenças coerente e consistente (DAVIDSON, 2001, p. 123-134). ${ }^{1}$

Destarte, poderíamos questionar-nos se um paciente que seguisse uma doutrina espírita e estivesse reticente quanto à ingestão de um determinado medicamento, por acreditar ser o seu problema decorrente de um carma, estaria ou não sendo racional. E se o doente perguntasse ao seu psiquiatra se valeria ou não a pena encaminhá-lo a um terapeuta de vidas passadas? Embora tampouco possamos acusar o nosso psiquiatra de irracionalidade, qual seria o efeito terapêutico em responder: "Veja, o que você tem é uma alteração do metabolismo de serotonina e precisa dessa medicação para se recuperar, caso contrário eu não vejo como ajudá-lo"?

Em meu entendimento, o que eu chamo de sintonização de sistemas de crenças não se restringe à dimensão ética, mas seria também muito útil no sentido terapêutico: maior adesão ao tratamento, menor índice de abandono 
da medicação, melhor qualidade de vida para o doente, mais confiabilidade no médico e seguimento adequado das prescrições. Todavia, ela deveria contar, como condição sine qua non, com a disponibilidade do médico em propiciar o entendimento mútuo. Na função, digamos assim, de intérprete, é dele que deve partir essa iniciativa. Para tanto, acredito que o psiquiatra deva assumir certas obrigações. Uma delas deveria ser a predisposição em compartilhar, de forma generosa e inteligivel, o que de seu conhecimento médico possa concernir ao seu paciente/interlocutor no "espaço" de consulta.

Boltanski já ressaltava que, frequentemente, o "mutismo" dos médicos incomoda sobremaneira os doentes. E a "barreira lingüística” que já os separa, devido ao desconhecimento, por esses últimos, da nosografia psiquiátrica, é geralmente complicada pela "atitude autoritária" dos primeiros, a qual redunda na sonegação até mesmo de informações mínimas pelas quais os seus pacientes poderiam dar um sentido aos misteriosos atos e prescrições (BOLTANSKI, p. 42 48). Por isso, ele propõe uma "educação sanitária" para os pacientes. Concordo; contudo, penso nisso em um sentido específico.

Sabe-se, por Davidson, que, ao interpretar os outros, é para os nossos próprios padrōes que nós nos voltamos, ou seja, para o nosso sistema de crenças. Diante de sua incapacidade de reproduzir, ou muitas vezes até de repetir textualmente o discurso do psiquiatra, o paciente constrói, por meio de um jogo de reinterpretações, as suas próprias representações da doença, que são, em geral, bem acabadas e coerentes com o seu sistema de crenças:

Bom dia doutor, é que eu tenho depressão sabe; meu cérebro é meio preguiçoso porque falta em meu corpo esse remédio que o outro psiquiatra sempre me passa. É problema de família sabe? Minha mãe também não tinha esse remédio no cérebro. Ele é bem forte, eu durmo o dia inteiro, mas em compensação ele faz os meus nervos funcionarem mais rápido, eu fico alegre e não choro mais o tempo todo. É que faltou medicação e eu vim pegar mais...” O senhor não vai mudar não né? É que uma vez um outro médico mudou o remédio; ele era muito fraco, o que eu tomava era de 75 (miligramas) e esse era de 25, mas ele mandou tomar; disse que era a mesma coisa. Não fez efeito nenhum, e aí eu comecei a esquecer as coisas, a minha cabeça ficou pesada, aí eu parei de tomar ele (Relato da primeira consulta comigo de uma paciente com um histórico psiquiátrico de cinco anos de evolução).

A paciente que proferiu o relato acima ignorava a diferença relativa da dosagem, em miligramas, entre as duas medicações, isto é, ela acreditava que essa diferença era quantitativa, e não qualitativa; isto é, pelo fato dele conter 25 miligramas 
de substância ativa, e não 75, como o anterior, aquele deveria ser mais fraco do que este e, portanto, não funcionar. Some-se a isso ela nunca ter sido informada, apesar dos cinco anos em que vinha se tratando, que a medicação antidepressiva requer muitos dias, às vezes semanas, para que surja o efeito terapêutico. Assim, já descrente da força do medicamento e convicta que, tal qual um analgésico, o seu efeito seria instantâneo, ela suspendeu a sua ingestão por conta própria, convencida de que aquele remédio, fraco, não a possibilitaria dormir bem. Ressalto, ainda, que ela não sabia que a medicação atuaria na depressão, e não na insônia - um sintoma, e não a causa dela. Em sua visão, o remédio lhe restituiria o humor por fazê-la dormir bem e não o contrário.

Como afirmei anteriormente, se Davidson diz que, na comunicação (refiro-me especificamente à relação médico-paciente), o que um falante e um intérprete devem compartilhar é um entendimento sobre o que o aquele quer dizer com o que fala, e se a racionalidade como coerência é o ajustar de um pensamento a outro, não vejo como alcançar um entendimento pela conversação, senão por meio do que Davidson chama de "compartilhar expectativas". Em suma, deve haver entre os falantes uma concordância sobre como cada um será compreendido. Assim, almejar uma sintonia entre sistemas de crenças - possibilitada de antemão pelo padrão de objetividade fornecido pela linguagem compartilhada - implica, a meu ver, testar crenças.

De nada adianta bombardear o paciente com jargões insólitos, e muito menos ordenar, valendo-se de sua autoridade: "Não me questione, apenas faça o que eu digo!”. O paciente não é irracional. Como a do próprio médico, a sua racionalidade consiste na consistência de seu sistema de crenças, isto é, na coerência de suas crenças umas com as outras. $\mathrm{O}$ médico pode, caso queira, permitir-se encontrar algo de seus padrões de pensamento no outro desde que esteja visceralmente disposto a testar o sistema de crenças de seu paciente. Pode, inclusive, aprender com as experiências dele.

A segunda obrigação de um psiquiatra realmente predisposto a facilitar o que Davidson chama de sintonização de sistemas de crenças poderia consistir em algo um pouco mais abrangente do que aceitar a seriedade das intençóes ou das solicitações de seu paciente em prol de um entendimento mútuo, eficaz para a coordenação da ação indispensável ao projeto de gestão compartilhada da medicação. É necessário, a meu ver, escutar "as dimensôes da experiência 
singular e das significações que estão associadas ao tratamento" (RRASMQ; ÉRASME, op. cit., p. 15); isto é, ouvir o sentido que os pacientes atribuem às suas experiências com a disposição semelhante à de um intérprete interessado em compreender uma pessoa que fala uma língua estrangeira desconhecida. Essa escuta encontraria, na narrativa, o leitmotiv da sintonização de sistemas de crenças, imprescindível à gestão compartilhada da medicação. Ela deveria ser, como diz Benjamin, ativa, braçal, e deveria implicar um esquecer-se de si mesmo.

Talvez utilizando ironicamente uma metáfora do mercado financeiro, o filósofo Walter Benjamin já havia dito, em um delicioso texto da história da filosofia, que "as ações da experiência estão em baixa, e tudo indica que continuarão caindo até que seu valor desapareça de todo.” (BENJAMIN, 1994, p. 198). A sabedoria, à qual ele se refere como "o lado épico da verdade", estaria em vias de extinção. Essa sabedoria, oriunda das experiências que passam de pessoa a pessoa, está deixando de ser comunicável. Consequentemente, na medida em que o narrador retira da experiência aquilo que ele conta, a narrativa estaria agonizando. "Quando se pede num grupo que alguém narre alguma coisa”, discorre Benjamin, "o embaraço se generaliza [...]. É como se estivéssemos privados de uma faculdade que nos parecia segura e inalienável: a faculdade de intercambiar experiências." (BENJAMIN, 1994, p. 197-198).

Diz a sabedoria popular que "quem conta um conto aumenta um ponto." Eis aí o espírito da narrativa. O que o narrador conta, a sua experiência ou a relatada pelos outros, ele incorpora à experiência dos seus ouvintes, que não resistirão a recontar a estória algum dia, à sua maneira, sem se preocupar em transmitir uma informação, em um contínuo processo de assimilação.

"Contar histórias sempre foi a arte de contá-las de novo" (BENJAMIN, 1994, p. 205). Quanto maior for a naturalidade com que o narrador conta as suas histórias, mais facilmente elas se gravarão na memória do ouvinte e se assimilarão à própria experiência do narrador. Quanto mais se esquecem de si mesmos, mais espontaneamente narrador e ouvinte tecem a teia que guarda o dom narrativo. Não é a toa que ele tenha surgido em um meio de artesãos, que narravam e ouviam na medida em que o trabalho manual se apossava deles. Segundo o filósofo, a narrativa seria um trabalho manual.

Contudo, embora o trabalho manual persista, a arte de narrar estaria desaparecendo, e com ela, o dom de ouvir - e os psiquiatras não estão, a meu ver, 
poderíamos chamar aqui de incorporação de experiências.

A importância de se levar em conta a experiência e as significações dos tratamentos farmacológicos, psicotrópicos e outros, entre as pessoas que os consomem, foi posta em evidência em estudos, mais numerosos nos últimos anos, que mostram o impacto das dimensões da experiência e das significações sobre as relações que se instauram face ao tratamento (mais ou menos conflitados, positivos ou negativos, passivos ou ativos), sobre o respeito ou não respeito das prescrições medicamentosas. (RRASMQ; ÉRASME, op. cit., p. 15).

$\mathrm{Na}$ medida em que os medicamentos psicotrópicos significam sempre qualquer coisa para a pessoa que os utiliza, para seu círculo social e para a sociedade como um todo, parece-me no mínimo relevante levar em conta as experiências e as significações plurais, e frequentemente contraditórias, que o tratamento medicamentoso enseja. A partir do ponto de vista dos usuários de medicamentos psicotrópicos, os seus aspectos simbólicos e os seus efeitos biológicos estão estreitamente interligados:

O remédio tem me feito bem, eu consigo me concentrar melhor no trabalho, a patroa tem se queixado menos de meu nervosismo, não tenho mais aqueles impulsos de partir para cima de alguém por causa de qualquer coisinha... mas eu tenho ficado meio lento, sabe... perdi aquela criatividade que eu tinha. Eu não o tomei ontem e perdi a cabeça com alguém no trânsito. Será que eu vou ter que tomar isso a vida inteira? (paciente em uso de estabilizador do humor)

É, melhorar, eu melhorei; daquela tristeza, da ansiedade, mas eu estou engordando muito e aí a minha autoestima fica lá embaixo. Meu namorado terminou comigo... Não tem um remédio que não engorde? Aquele que o senhor me sugeriu, dizendo que não engordava, é muito caro e o senhor sabe né, eu sou funcionária pública e o meu dinheiro não deu. Eu nem comprei. Como eu ainda tinha uns comprimidos do antigo eu voltei a tomá-lo, mas eu não posso continuar engordando assim, tenho vergonha até de sair de casa (paciente em uso de antidepressivo).

- Olha doutor, esse remédio eu estou tomando dia sim dia não, mas tenho ficado meio irritada, desanimada...

- É porque você não o está tomando da forma adequada.

- Mas é que ele me tira a libido sabe... Eu melhorei cem por cento, com ele, mas o meu marido tem se queixado constantemente..."

- Podemos tentar outro então... (receito-lhe outro medicamento).

- Mas quanto custa doutor?

- Custa "tanto" (digo-lhe o preço por alto).

- Ah, mas aí não dá. Então eu vou parar de tomar remédio. O outro eu pego no posto de saúde; eu estou desempregada...” (paciente em uso de antidepressivo). 
Atentar para essas complexas correlações entre aspectos simbólicos e efeitos biológicos dos medicamentos não significa só escutar as experiências e significações dos pacientes em uso de medicação em prol de um entendimento mútuo. Ora, essa escuta à qual me refiro deveria ter, segundo o meu entendimento, uma dimensão ativa. Considerando-se, por exemplo, esse último diálogo, diante do impasse, eu poderia argumentar com a paciente: "Sim eu compreendo o seu problema, mas não vejo muito que fazer. Você deve pensar a sua decisão em termos de custo e benefício: o que é pior, a perda da libido ou a depressão?" Todavia, optei por testar o seu sistema de crenças visando o compartilhamento:

- Deixe-me ver se eu compreendi. Então o problema da libido depende só de você?

- O meu marido tem se queixado. Mas ele também não se empenha muito em me entender...

- Como assim?

- Ah, o senhor sabe né? O remédio me deixa meio gorda..., ele não demonstra muito interesse. Aí eu mesma não me sinto bem com a minha forma física... e aquele jeito com que ele faz, meio que por obrigação, parece... É que quando eu estava deprimida aceitava tudo e achava que ele me fazia um favor, achava que eu era feia, que ele poderia se cansar de mim e arranjar outra...

- Então o problema não é só o remédio? É isso?

- Ele toma o Viagra lá dele e diz que eu não tenho do que me queixar...

- Então o problema é seu?

- Eu acho que ele poderia me entender melhor... O senhor entende o que eu quero dizer? Eu estou cansada do jeito que ele faz...

- Quando você estava deprimida você não se importava?

- Eu me importava, mas aceitava...

- E hoje você já não aceita mais? Será que é porque você melhorou da depressão, ou o fato de não aceitar é um outro problema que poderíamos resolver com remédios?

- Eu acho que não né? Eu não havia pensado nisso dessa forma.

- Quem sabe uma conversa com ele a respeito...?

- Deixe-me ver se eu entendi o que o senhor está querendo dizer; então por estar melhor eu não estou aceitando mais algo que antes eu aceitava devido à minha doença? $\mathrm{Na}$ verdade, o nosso casamento tem problemas há algum tempo...

- Então você acha que a solução seria interromper a medicação, voltar a se deprimir e assim dar um ponto final ao problema da sua libido?

- Não, ora, isso não ia adiantar nada, óbvio; é que antes eu aceitava o jeito dele. 
- Então o problema da libido já existia antes?

- Eu acho que sim...

- Mas, na ocasião, você o tomava para si, é isso? Então ter melhorado da depressão a fez se dar conta de alguma coisa?

- Eu acho que ele tem que me entender também. Mas o remédio não tira um pouco a libido?

- Pode acontecer. Mas será que é só o remédio? Será que a sua melhora e a consequente perda da libido não podem indicar outra coisa?

- O problema da nossa relação mal-resolvida...

- Essa é a sua conclusão? O que fazer então? Trocar o remédio para que a sua libido volte?

- Eu acho que sempre achei que o problema era meu. É sempre da mulher né? Se for deprimida então...

- Não deixa de ser, afinal, você vai ter que dar uma solução a ele, ou pelo menos você não pode mais ignorar a sua dimensão. Ah, espere, tem umas amostras grátis aqui em minha gaveta... Esse aqui não dá problemas com a libido. Vamos tentar?

- Não, espere um pouco, eu melhorei da depressão com aquele: saio de casa, trabalho, passeio com a minha filha; depois, e se não der certo? O remédio demora um tempo para fazer efeito... Eu acho que vou tentar conversar com ele sobre esse problema da minha libido... Quero entender isso melhor.

Logo após a consulta acima relatada, refletindo sobre a maneira como eu a havia conduzido, de forma não planejada, e até mesmo inusitada, ocorreu-me, de súbito, que logo antes eu lera um texto denominado The Socratic Elenchus (VLATOS, 1982, p. 711 - 714). Embora eu não faça ideia do quanto esse artigo possa ter influenciado a minha atuação clínica, acredito que o elenchus possa lançar uma luz sobre o desenlace da entrevista. Em sua análise do método socrático, o autor afirma, segundo a interpretação de Davidson, que "a lógica do elenchus não pode fazer mais do que revelar inconsistências.” (DAVIDSON, 2005, p. 242) Davidson segue dizendo que:

O que os diálogos nos mostram de novo e de novo, é que Sócrates é hábil em mostrar que seus interlocutores são confusos, que suas pretensões em saber o que é piedade ou coragem ou virtude estão equivocadas à luz de outras perspectivas que eles mesmos sustentam. A sabedoria que é obtida é totalmente negativa: um número de falsas perspectivas são reveladas como tais, mas o elenchus nunca é mostrado como conduzindo à uma verdade moral maior. (DAVIDSON, 2005, p. 246-247, grifos meus).

Ele então conclui que as sérias crenças morais firmemente sustentadas por um indivíduo são verdadeiras, na medida em que as "criaturas racionais, 
criaturas com pensamento, devem ser amplamente consistentes e corretas nas suas crenças" (DAVIDSON, 2005, p. 245), ou seja, os seus sistemas de crenças devem ser coerentes, por serem criaturas pensantes.

Observe que, no diálogo acima, a crença de que o remédio lhe causa perda da libido não se dissocia do desejo de interrompê-lo, ou de substituí-lo, com o intuito de recuperá-la. Contudo, na conversação essa crença mostrou-se inconsistente à luz de outra perspectiva dela mesma e a paciente percebeu não só que a perda da libido poderia estar relacionada a outros fatores, como também que ela não seria a única, digamos assim, culpada, haja vista ter-se dado conta de que a relação já estava desgastada há um certo tempo. Além disso, surgira o insight de que a medicação, que lhe fizera bem, teria sido responsável pela sua nova atitude frente a um relacionamento insatisfatório, ainda que ela lhe soasse, a princípio, como um problema exclusivamente seu, e essencialmente biológico. O que eu gostaria de ressaltar aqui é o compartilhamento de crenças que a conversação engendrou:

Assim, nosso entendimento dos valores dos outros depende bastante do que é compartilhado, para nos permitir dar sentido ao que não o é, e para fornecer bases legítimas para a resolução de diferenças morais. Isto vale, naturalmente, somente na medida em que nós realmente entendemos os pensamentos e valores do outro. Para tomar o mais simples caso e compreendê-lo de uma forma que requer muita elaboração antes que possa ser aceito. (DAVIDSON, 2005, p. 245-246).

Segundo Davidson, uma pessoa confusa, dizendo coisas contraditórias, não está necessariamente errada, ela simplesmente não sabe o que ela pensa; e então explica: "nós não temos pensamentos claros, exceto quando eles são excitados no processo de ser compreendido pelos outros", pois, “o conteúdo dos pensamentos e dos juízos das pessoas depende de suas relações com as outras pessoas e com o mundo" (DAVIDSON, 2005, p. 249).

Em sua análise, ele sugere que Sócrates acreditava visceralmente na troca verbal como o principal, ou único, acesso à sabedoria moral. Em suma, ele afirma que "quanto mais nós entendemos os outros, mais nós sabemos o que pensamos" (DAVIDSON, 2005, p. 250). Nesse ponto, gostaria de ressaltar que nós, psiquiatras, também poderíamos aprender com os nossos pacientes, pois nós recorrentemente encontramos uma chance de reformular o nosso sistema de crenças a partir das interlocuções clínicas. Tal qual Sócrates, em Cármides, que redargui, em resposta à acusação de Crítias, de que ele o refutara sem ouvir o seu 
argumento: "Como você pode pensar que eu tenha qualquer outro motivo em refutar você exceto esse que eu deveria ter ao examinar a mim mesmo?”.

De fato, na situação clínica que descrevi, a paciente se dera conta, na conversação, de algo que ela não sabia que sabia; ou seja, ela reformulou algumas de suas crenças acerca da medicação, de sua sexualidade e também da psiquiatria. Quanto a mim, algo nesse sentido também se realizou. Acredito que o imprevisivel me permitiu rever, por exemplo, a idéia pré-concebida de que diminuição da libido corresponde, necessariamente, ao efeito da medicação.

Segundo Gadamer, o diálogo também pode ser tratamento, e, enquanto tal, só é terapêutico se não for conduzido por ninguém, mas sim conduzir, no autêntico envolvimento no processo de cura (GADAMER, 2006, p. 142):

$[\mathrm{N}]$ ela, os dialogantes são menos os que dirigem do que os que são dirigidos. O que 'sairá' de uma conversação ninguém pode saber por antecipação... são formas de expressar que a conversação tem seu próprio espírito e que a linguagem que nela discorre leva consigo a sua própria verdade, isto é, 'revela' ou deixa aparecer algo que desde este momento é. (GADAMER, 1997, p. 559).

O diálogo terapêutico suscita uma possibilidade, a palavra apropriada que responde à situação do momento, em suma, à "verdade" que se produz na situação. De acordo com a interpretação gadameriana de Aristóteles, revela a phronesis, ou seja, o "sentido para a colocação dos próprios fins" (GADAMER, 2006, p. 54, 55 e 143). Nisso consistiria o saber prático da arte de curar.

Em outras palavras, poderíamos inferir que, na gestão compartilhada da medicação, o que a conversação terapêutica pode fazer é suscitar a irrupção do sentido como um "por-se de acordo sobre a coisa, não deslocar-se para dentro do outro e reproduzir as suas vivências" (GADAMER, 1997, p. 559). Isso significa que o sentido que o paciente produz é "autêntico", é um caminhar com as próprias pernas; ou seja, ele não é definido em correspondência ao "uso linguístico” especializado da psiquiatria científica (GADAMER, 2006, p. 52). Logo, o cuidado entrevisto no diálogo terapêutico implica o reconhecimento do outro como "ser diferente".

Isso transforma a relação médico-paciente em uma autêntica parceria com o mundo-da-vida, que engendra uma "capacidade para si mesmo", muitas vezes inconsciente. A meu ver a reflexão acerca de uma gestão compartilhada da medicação em saúde mental poderia ensejar uma maior atenção ao que Trisha Greenhalgh chama de clínica baseada em narrativas (SERPA JR., 1999, p. 73). 


\section{Referências}

BENJAMIN, W. O narrador. Consideraçōes sobre a obra de Nikolai Leskov. In:

Magia e técnica, arte e política: ensaios sobre literatura e história da cultura. São Paulo: Brasiliense, 1994.

BOLTANSKI, L. As classes sociais e o corpo. Rio de Janeiro: Graal, 1979.

CHARMIDES. Disponível em: http://www.filoinfo.bem-vindo.net/plotinus/node/484.

DAVIDSON, D. Three Varieties of Knowledge. In: Subjective, Intersubjective,

Objective. New York: Oxford University Press, 2001.

. Paradoxes of Irrationality. In: Problems of Rationality. New York: Oxford University Press, 2004.

. The Socratic Concept of Truth. In: Truth, Language, and History. New

York: Oxford University Press, 2005.

GADAMER, H-G. O caráter oculto da saúde. Petrópolis: Vozes, 2006.

Verdade e método. Petrópolis: Vozes, 1997.

HABERMAS, J. Verdade e justificação: ensaios filosóficos. São Paulo: Loyola, 2004.

. A ética da discussão e a questão da verdade. São Paulo: Martins Fontes, 2007.

PIGNARRE, P. O que é o medicamento? Um objeto estranho entre ciência, mercado e sociedade. São Paulo: Ed. 34, 1999.

RORTY, R. Objetivismo, relativismo e verdade. Rio de Janeiro: Relume-Dumará, 1997.

REGROUPEMENT DES RESSOURCES ALTERNATIVES EN SANTÉ MENTALE DU QUĖBEC. ÉQUIPE DE RECHERCHE ET D'ACTION EN SANTÉ MENTALE ET CULTURE. Repères pour une gestion autonome de la médication en santé mentale: guide d'accompagnement. Quèbec: Bibliothèque et Archives Nationales du Quèbec, 2006.

SERPA JR., O.D. Clínica e evidência: em que se baseiam as nossas decisões? Cadernos do IPUB, n. 15, p. 61-78, 1999.

VLASTOS, G. The Socratic Elenchus. The Journal of Philosophy, v.79, n.11, Nov. 1982.

\section{Nota}

${ }^{1}$ Entretanto, como falar em "racionalidade" em se tratando de doentes mentais, ou até mesmo em pessoas supostamente saudáveis? De acordo com Davidson, citando Hobbes, o "paradoxo da irracionalidade" consiste em que "somente uma criatura racional pode ser irracional" (DAVIDSON, 2004, p. 169). Ele desenvolve o argumento alegando que "o tipo de irracionalidade que causa problema conceitual não é a falha de algum outro em acreditar, ou sentir, ou fazer o que nós consideramos razoável, mas antes a falha, inerente à mesma pessoa, de coerência ou consistência no padrão de crenças, atitudes, emoções, intenções e ações" " "The sort of irrationality that makes conceptual trouble is not the failure of someone else to believe or feel or do what we deem reasonable, but rather the failure, within a single person, of coherence or consistency in the pattern of beliefs, attitudes, emotions, intentions, 
and actions." (DAVIDSON, 2004, p.170). Para ele, age irracionalmente aquele que conscientemente

e intencionalmente age contra o seu próprio princípio, ou contra o seu melhor juízo (DAVIDSON, 2004, p. 177): Se um agente acredita que A é melhor do que B, então ele quer fazer A mais do que B. Se um agente quer fazer $A$ mais do que $B$, então ele fará $A$ ao invés de $B$, se for fazer uma das duas coisas. Mas, às vezes um agente age contra seu melhor juízo e faz $\mathrm{B}$. Nisso consistiria a akrasia socrática. Caso o ato acrático não fosse intencional, o agente em questão não poderia ser por ele responsabilizado, na medida em que uma força estranha tomara conta de sua vontade; o que Davidson chama de "princípio de Medeia". Mas não seria esse o caso em alguns transtornos, como a esquizofrenia, por exemplo? Não o sabemos (pois não está claro que no delírio de influência, por exemplo, o esquizofrênico não age intencionalmente [afinal, a força externa toma conta de sua vontade ou vai contra ela?]); mas mesmo que assim o seja, concordo com Davidson que, embora o motivo para ignorar um princípio seja uma razão para ignorar o princípio, não é, necessariamente, uma razão contra o próprio princípio; isto é, "a irracionalidade depende da distinção entre uma razão para se possuir, ou agir de acordo com, um princípio, e uma razão para o princípio (DAVIDSON, 2004, p. 178). Um paciente, obviamente delirante, me diz: "Sinto muita raiva por não me deixarem trabalhar; eu queria tanto". "E por que não o faz?" Pergunto-lhe tolamente. "Ora doutor...", responde-me, visivelmente irritado, “o senhor acha sinceramente que eu tenho condiçôes de trabalhar assim?”Esse paciente é racional ou irracional? Em outro exemplo, se alguém acredita que é Deus, esse alguém pode ter uma razão para querer ter essa crença: isso lhe dá prazer. Todavia, o seu desejo não racionaliza a sua crença, ou seja, não só não é evidência para a verdade de sua crença como também não lhe fornece, de modo algum, um suporte racional. Destarte, ainda que alguém aja contra o seu melhor juízo (ou ainda que os prós e contras coexistam em ambivalência), isso não significa necessariamente que esse alguém não tenha um sistema de crenças coerente a partir do qual ele possa estar ambivalente: "Eu tenho duas identidades", disse um paciente meu, reticente. "Como assim?", eu lhe perguntei. "Como é que eu vou fazer para pagar as minhas contas, votar, ou mesmo assinar um cheque?", perguntou, desesperado. "Não estou entendendo?", interroguei-o, perplexo. "É que eu perdi o meu RG; mandei fazer uma cópia, mas na semana passada encontrei o primeiro. Agora eu tenho duas identidades! Como eu poderei viver assim de agora em diante?" Será que poderíamos afirmar que esse paciente não tem um sistema de crenças coerente, ou ele está mascarado por uma ignorância da distinção de que Davidson nos alertou? Ora, se ele acredita que necessita do RG para votar e deseja fazê-lo... De forma análoga, acredito que o psiquiatra poderia considerar seriamente este "paradoxo da irracionalidade"; pois, se por um lado ele explicar bem demais a suposta irracionalidade de seu paciente, ele a transforma em uma forma dissimulada de racional; se, por outro, ele lhe atribui incoerência, ele compromete a sua própria habilidade em diagnosticar a irracionalidade - por retirar o pano de fundo de racionalidade necessário para isso. 


\title{
Abstract
}

\author{
In defense of a shared management of \\ medication in psychiatry \\ Based on a discussion of the Guide to Monitoring \\ Autonomous Management of Medication in Mental Health, \\ resulting from a comprehensive mental health project \\ subsidized by the Ministry of Health of Canada, I \\ propose to support the clinical relevance of what I prefer \\ to call shared management of medication in mental health.
}

> Key words: medication; psychiatry; life quality; mental health; collective health 